\title{
Impact of the Covid-19 Pandemic on Mental Health Among Medical Frontliners Working in Metro Manila
}

\author{
Duran, Eryl $^{\mathrm{a}}$, Dollentas, Enya ${ }^{\mathrm{b}}$, Lansangan, Therese ${ }^{\mathrm{c}}$, Rebua, Lalaine ${ }^{\mathrm{d}}$, Rojas, \\ Sophia ${ }^{\mathrm{e}}$, Sampana, Luc ${ }^{\mathrm{f}}$, Pagud, Anna Liezle T., RMT, MD, MPH ${ }^{\mathrm{g} *}$ \\ a eryljoy.duran.pharma@ust.edu.ph. ${ }^{g}$ atpagud@ust.edu.ph \\ ${ }^{\text {abcdefg }}{ }^{2}$ epartment of Medical Technology, Faculty of Pharmacy, University of Santo Tomas, Smpaloc, Manila, Philippines, 1008
}

\begin{abstract}
The COVID-19 pandemic has taken its toll on everyone's mental health. The medical frontliners, being one of the most exposed individuals to the virus, take on a high risk of facing a mental health crisis. Therefore, it is crucial to assess their mental health status. This study determines the impact of the COVID-19 pandemic on the mental health of the medical frontliners in Metro Manila. To gather data, adopted questionnaires: Depression, Anxiety and Stress Scale (DASS-21) and Impact of Event Scale with Modifications for COVID-19 (IES-COVID19) were utilized. These were disseminated through google forms via email. The data gathered were subjected to statistical analysis, with the help of statisticians, through Statistical Package for the Social Sciences (SPSS) Software. In this study, the statistical tools used were frequency, percentage, T-test, One-Way ANOVA, and regression analysis. From the results obtained, there were no significant differences in the demographic profiles, except for Anxiety before the pandemic and Stress during the pandemic in terms of age, and Anxiety and Stress before the pandemic in terms of the length of service. Based on the DASS-21 and IES-COVID19, the COVID-19 pandemic has a significant impact on the mental health of medical frontliners. There was an increase in terms of respondents with "normal" results during the pandemic in comparison to pre-pandemic. According to regression analysis, the greatest impact of COVID-19 can be seen in depression, followed by anxiety, and stress. This knowledge can help in raising awareness regarding the mental health of medical frontliners and in assessing the appropriate interventions and protocols in healthcare institutions, especially during pandemic periods.
\end{abstract}

Keywords: Mental Health; Covid-19; Medical Health Workers, Medical Frontliners

\section{Background of the Study}

\subsection{Introduction}

Novel Coronavirus (2019-NCoV) is an infectious disease that first occurred in Wuhan, China in December 2019. It is a new strain of coronavirus that has not yet been identified before. It is spreading easily through person-to-person contact, specifically through respiratory droplets when an infected person coughs or sneezes (Centers for Disease Control and Prevention, 2020). According to the World Health Organization, the Philippine Department of Health reported its first case of coronavirus in January 2020 from a 38-year-old Chinese woman. The COVID-19 pandemic has taken its toll for most people. More 
than 100 million people suffer from mental health disorders in the Western Pacific Region. For many people, getting the support they need is difficult (WHO, 2020).

As of August 28, 2020, there were 24, 299, 923 confirmed cases and 827, 730 deaths across the globe. Meanwhile, in the Philippines, from January 2020 to August 28, 2020, there have been 205, 581 confirmed cases and 3, 234 deaths (WHO, 2020). According to the research conducted by Leodoro Labrague, among the ASEAN countries, the Philippines is the second leading country in terms of cases and deaths. With this, our healthcare workers have been facing pressure and challenges brought upon by the pandemic that could affect their performance and overall well-being. Note that in developing nations such as the Philippines, our healthcare systems are overburdened and poorly resourced as compared to developed countries. Most of our healthcare systems have suboptimal diagnostic and therapeutic capabilities such as fewer bed capacity and laboratory infrastructure (Walcott \& Schamroth, 2020). Due to this, our medical frontliners are faced with different challenges such as toxic cultural environment, stress, poor job design, lack of hazard pay, exposure to numerous deaths. These all contribute to causing mental health problems to healthcare workers (Baron, 2020). They are continuously facing numerous deaths due to the severity of the virus. Exposure to these situations may lead to trauma and psychological stress and pressure. In an article by Manila Bulletin entitled, "COVID-19 wreaks havoc on healthcare workers' mental health", it was mentioned that most health care workers who are experiencing mental health problems are now experiencing body fatigue, lack of sleep, muscle pain, headache, and poor immune system. Furthermore, our medical community voiced their plea for a timeout as there is a surge of coronavirus infections in the country, which has now exceeded the 100,000-mark (Bonquin, C, 2020). Now, more than ever, is the time for us to hear the request of our healthcare frontliners, whether it is a call out to the government or to the public. We cannot afford our healthcare system to collapse because the moment they are defeated, our entire nation is also defeated (Bonquin, C, 2020).

In line with this, the researchers aim to tackle the impact of COVID-19 pandemic on mental health among healthcare frontliners working in Metro Manila. Through Google forms, the researchers provide electronic questionnaires and conduct a survey test regarding the effect of Coronavirus in the mental health of healthcare workers in Metro Manila, where there is a rapid increase of infection. In this research, the proponents gather the demographic profile of Healthcare workers working in Metro Manila to identify which factors which affect their mental health, as well as to assess the impact of Coronavirus in their mental health, and lastly, to identify their needs in terms of their mental health.

The Covid-19 pandemic has altered various protocols relating to the field of medicine including the stringent adherence to novel safety guidelines. Moreover, the exponential growth of cases in the country has stirred the workload of health workers particularly in epicenters such as Metro Manila. According to the World Health Organization (2002), the accountability of mental health disorders on productivity and health has long been underestimated. In line with this, the researchers have determined to conduct a study concerning the significant change in the health worker's mental well-being before and during the pandemic. The results determined if the COVID-19 pandemic has a significant impact on the mental health of Medical Frontliners working in Metro Manila.

\subsection{General Objective:}

The study aims to determine the impact of the Covid-19 pandemic to the mental health status of the medical frontliners working in Metro Manila. 


\subsubsection{Specific Objectives:}

Specifically, this study aims to:

1. Identify the demographic profile of the medical frontliners working in Metro Manila, including:
a. age;
b. gender;
c. civil status;
d. occupation;
e. length of service; and
f. place of service.

2. Determine the significant difference between demographic profiles in terms of depression, anxiety, and stress.

3. Recognize the mental health status of medical frontliners during the pre-pandemic and pandemic period.

4. Determine the impact of Covid-19 pandemic to the mental health of the medical frontliners in terms of:
a. depression;
b. anxiety; and
c. stress.

\subsection{Research Problem (General and Specific)}

This study seeks to determine the impact of the Covid-19 pandemic on mental health among medical frontliners. Specifically, it will answer the following questions:

of:

1. What is the demographic profile of the medical frontliners working in Metro Manila in terms

1.1 age;

1.2 gender;

1.3 civil status;

1.4 occupation;

1.5 length of service; and

1.6 place of service?

2. Do the different demographic profiles have a significant difference in terms of their depression, anxiety, and stress?

3. What is the mental health status of medical frontliners during the pre-pandemic and pandemic period?

4. What is the impact of the Covid-19 pandemic on mental health among medical frontliners in terms of:

1.1 depression;

1.2 anxiety; and

1.3 stress?

\subsection{Significance of the Study}


To the students. The study will help students widen their perspective about mental health. This will help the students to be more conscious not just of their own mental health status but also the people around them.

To society. The study will help spread more awareness regarding the mental health of the medical frontliners amid the pandemic. The topic will widen society's perspective on the mental health of one another. It will also help them be more empathetic to the health workers not just during pandemic. This will help the netizens realize the importance of mental health and its impact on oneself.

To the medical frontliners. The study will fixate on the importance of mental well-being among health care workers which can be a parameter on developing interventions and advancement of protocols inside a healthcare institution to progress the efficiency and capability of healthcare workers on bringing relevant, accurate, and timely diagnosis and treatment. Through this, the management can alleviate particular tasks that are not efficient in terms of providing services.

To the future researchers. The study will serve as reference for their future research about the effects of pandemic on the mental health of medical frontliners.

\subsection{Scope and Limitations}

This study was conducted for the purpose of determining the impact of Covid-19 pandemic on the mental health of Medical Frontliners working in metro manila.

The design utilized in this study is quantitative. The researchers made use of an adopted questionnaire and data gathered through an online survey deployed through Google Forms. The focus of this study were the Medical Frontliners working in Metro Manila. To determine the participants of this study, a convenience sampling method was used. Respondents were selected from private and public hospitals, and other medical facilities within the cities of Metro Manila, namely, Caloocan, Malabon, Valenzuela, Quezon City, Marikina, Pasig, Taguig, Manila, Mandaluyong, San Juan, Pasay, Las Piñas, and Muntinlupa city.

This study, however, is subject to several limitations. First, the study was limited to Medical Frontliners who are actively working in a public or private hospital, laboratory, and Covid-19 facility within Metro Manila. Also, the study did not include those Medical frontliners who are working in an administrative position as well as those who are participating in telemedicine only, and are not exposed to the hospital/COVID-19 facilities. The second limitation concerns the scarcity of existing studies on this topic as Covid-19 is a relatively new public health issue. Lastly, the convenience sampling procedure decreased the generalizability of findings. The study would not be representing the entirety of Medical Frontliners in Metro Manila.

\subsection{Research Hypothesis}

- Null Hypothesis: COVID-19 pandemic has no significant impact on the mental health of medical frontliners in Metro Manila.

- Alternative Hypothesis: COVID-19 pandemic has a significant impact on the mental health of medical frontliners in Metro Manila 


\section{Nomenclature}

A. Anxiety. "An emotion characterized by feelings of tension, worried thoughts and physical changes like increased blood pressure".

B. Depression. An emotional state of feeling a heaviness, and merely a lowering of mood or spirits.

C. Frontliners. Employees of essential industries in which their physical presence is needed.

D. Health. A state of complete physical, metal, social well-being and not merely the absence of disease or infirmity.

E. Medical Frontliners. Health workers that provide routine essential medical care.

F. Mental Health. A state of well-being in which every individual realizes his or her own potential, can cope with the normal stresses of life, can work productively and fruitfully, and is able to make a contribution to her or his community.

G. Novel Coronavirus (2019-NCoV or SARS-CoV-2). A newly discovered respiratory diseasecausing virus from the Coronavirus family which causes a highly contagious disease that can spread from person-to-person. It is the causative agent of Coronavirus Disease.

H. Stress. The feeling of overwhelm to the point of being unable to cope brought about unimaginable internal and external pressures.

\section{Introduction}

\section{Mental Health of the Medical Frontliners During the Pandemic}

\subsection{Pandemic}

\subsubsection{Covid-19}

The world was never prepared for a pandemic like the COVID-19. There are already over 2.3 million confirmed cases and 160,000 confirmed deaths (Vigo, 2020). Affected countries closed their borders to contain the virus, contact tracing, physical distancing, as well as isolation were also used. However, despite these measures, everyone's health seems to be spiraling down, especially people's mental health. In an article "Mental Health of Communities during the COVID-19 Pandemic", it was mentioned that pandemics have been known to be affecting mental health. "Parallel epidemic" is what they call mental problems that are triggered by outbreaks such as COVID. According to Vigo, there are 4 subtypes according to the population affected: people with substance use disorders, individuals who provide essential services, the general public, and infected individuals. However, this study would be focusing on people who provide the necessary services needed for the pandemic and are at the highest risk of infection. 
The people who provide the necessary services, especially the medical workers, put their lives at risk everyday just so others could live theirs. Health personnel always suffer from their job because it entails increased exposure to infection, stressors, and trauma. UK experts now estimate that a third of infections are concentrated in health care workers (Vigo, 2020). Because of insufficient equipment and longer working hours due to the increased number of patients, frontliners are at risk of contracting the virus. They are also forced to make life-or-death decisions twice as much as they used to. They also do not have time to process all the losses they have encountered due to the amount of work. This may then cause extreme stress, fatigue, and preexisting conditions such as post-traumatic stress disorder and anxiety may become severe. With this, Vigo mentioned that "specialized care for health workers should be prioritized and readily available". The pandemic only highlighted that mental health should be a fundamental component of universal health coverage for this will improve the systems' capacity of responding to threats such as COVID-19 (Vigo, 2020).

\subsubsection{Other Pandemic/Epidemics}

Severe Acute Respiratory Syndrome (SARS) was known as the first severe and transmissible new infectious disease in the course of the twentieth century which was first discovered in November 2002 in Guangong, China. However, it was only recognized as a threat when the spread of infection reached Vietnam. In addition to that, there is also an occurrence and increase of infection in different countries around the world such as in China, Hongkong, Taiwan, Canada and Singapore which are the most affected countries by the said disease with a total cases of $5327,1755,346,251$ and 238 in each respectively as reported on July 3, 2003. (Kuriansky, 2016)

The impact of the SARS epidemic is very significant not only in terms of physical dangers and death toll but also on its psychological impact. Nervousness, panic, anger and pessimism were experienced by the people of Beijing as well as irrational behaviors which includes storing cash, hoarding food and excessive checking of their temperature. There was an increase of $10 \%$ in terms of the traumatic stress levels in correlation to their feelings of helplessness and anxiety especially in healthcare workers. High risk HCWs experienced higher stress levels than low risk HCWs. Furthermore, an increase of stress was also reported on family and work settings as a result of fears of contagion which was reflected in social distancing and high job absenteeism. Moreover, avoidance of SARS patients, suspected patients, isolated people, medical staff and their families were experienced. In addition to the already outstretched health care resources, HCWs start to develop the disease. Studies have shown that $26.6 \%$ of the 1,192 SARS patients were hospital workers. In another study, researchers found out that the increasing distress among HCWs are result of the extreme working hours and conditions on SARS isolated wards, higher risk of getting infected through medical procedures and the biases and stigma caused fears and behaviors such as excessive testing of their physical conditions, repeated administration of hygiene measures and feeling sick easily. When HCWs were presented with a SCL-90 assessment scale, it was observed that variables such as hostility, suspicion, projection, uncomfortability and inferiority were high. This prompted the researchers to conclude the need for self-care, training and support of HCWs to cope up with the emotions produced by the epidemic. (Kuriansky, 2016)

Healthcare workers were vulnerable to developing mental health symptoms as they treated outbreak victims. This can be proved through high levels of stress reported wherein $11 \%$ of HCWs had traumatic stress reactions such as depression, anxiety, hostility, and somatization symptoms. Moreover, it was mentioned that adverse psychological effects on HCWs can be reduced when they are ensured to receive 
correct knowledge and information to be able to understand the infectious disease, to be provided with PPEs and given access to both medical and mental health support and resources. It was also highlighted that there should be adequate HCWs capacity during response to crisis situations. (Morganstein et al., 2017).

In 2014, an Ebola outbreak occurred which was considered to be the largest and deadliest outbreak in recorded history. Ebola virus is highly infectious and virulent in nature, it progressed rapidly and brought fear throughout the international community because of its high fatality rate. According to the CDC Case counts page, it is responsible for the killing of more than 11,000 people which consists of citizens and aid workers before it was contained in 2015. The United Nations Security Council declared Ebola as a global threat to international security which led to the initiation of a global public health response which brought HCWs and aid workers from different parts of the globe to Africa. Due to the worsening impact of the Ebola outbreak in West Africa, patients who exhibit symptoms began to escape from their treatment facilities, families started to hide their sick relatives in their homes as they preferred traditional healers and there is also physical contact with infectious corpses. These alarming situations caused severe concern among HCWs as there was an increasing rate of infection and death due to exposure to patients. By late December 2014, statistics have shown that there were 649 infected patients and 365 deaths. Following these catastrophic events, there was an increased risk in the adverse psychological symptoms of HCWs. Workers who are in the front line of the disease, which are responsible for infected Ebola patients, were vulnerable because of inadequate PPEs, fear and stigmatization from their families and friends. Furthermore, there is the constant risk of contracting the fatal disease. Anger, anxiety and insomnia were experienced by HCWs infected with the disease. Another important factor is the stress from repeatedly being gowned, gloved and masked in a hot environment while providing care to patients which may result in breakdown of care leaving providers' feeling guilty, withdrawing emotionally and collapsing morale. High chance of care delivery failure occurs when resources are poor and there is inadequate social and emotional support for caregivers at risk. Lastly, a profound shortage of mental health providers was also a challenge in the Ebola outbreak. Two of the most impacted countries in West Africa, Sierra Leone and Liberia, with a combination of more than 10 million citizens, have only one psychiatrist each, dozens of mental health nurses and an estimated 100 paraprofessionals trained in assessing and managing common mental disorders, which is the role of trained, knowledgeable mental health personnel were acknowledged as essential in the community experiencing distress in times of outbreaks. (Morganstein et al., 2017)

\subsection{Mental Illness}

Health has been viewed as the physical capability of a person to cater his day-to-day-life. Oftentimes, discussions on mental health are disregarded as it is deemed extraneous to overall health. However, the definition given by the World Health Organization being "a state of complete physical, mental, and social well-being and not merely the absence of disease or infirmity" (WHO, 1948) did not overlook the importance of having a complete mental well-being. Over the last half-century, changes in the definition of mental illness emerged. Mental illness has been defined as any condition affecting a person's cognition, emotion, and behavior. Several social determinants of mental health and illness affecting the mental wellbeing of a person include income, stress, discrimination, social support, and occupation (Manderscheid, et. al., 2009). Among those, occupation is a top priority due to the current outbreak of COVID-19. Medical front liners are the backbone of a healthcare system. The pressure accompanying the responsibility given to them may affect their overall well-being as it may pose a risk in developing mental illnesses. Prevalence of 
mental illness is high among medical front liners. Studies show that higher risk in developing psychiatric illnesses are common in healthcare workers in emergency units, intensive care units, and infectious disease wards (Naushad et al., 2019). Depression, anxiety, and insomnia are some of the mental illnesses rampant among healthcare workers during the COVID-19 pandemic (Pappa et al, 2020). Even before the COVID-19 outbreak, stress has been present in the daily lives of healthcare workers. The nature of their occupation deemed it inevitable as they are presented daily with high levels of pressure. But because of the sudden outbreak of the pandemic, the already existing stress has been magnified.

\subsubsection{Depression}

Depression has been defined as an emotional state of feeling a heaviness, and merely a lowering of mood or spirits (Simpson \& Weiner, 1989). Symptoms may be characterized by a depressed mood, loss of interest, and decreased energy and fatigue (Paykel, 2008). It is one of the common mental illnesses across populations. An estimated 3.8\% of the world's population live with depression. WHO ranked it as the single largest contributor to global disability (Stringaris, 2017). In a systematic review and metaanalysis done by Salari et. al. (2020), depression during the COVID-19 pandemic had a prevalence of $33.7 \%$ (95\% CI, 27.5-40.6) among the general populations in Asia and Europe. As for the medical frontliners, a systematic review and meta-analysis on the prevalence of depression among healthcare workers during the COVID-19 pandemic was conducted by Pappa et.al. (2020) in which ten studies from China and Singapore were assessed. Studies show that depression has a prevalence rate of $22.8 \%$.

\subsubsection{Anxiety}

The American Psychological Association defined anxiety as, "an emotion characterized by feelings of tension, worried thoughts and physical changes like increased blood pressure". Recurring intrusive thoughts and concerns are common among people with anxiety disorders. Although it is less visible than the other mental illnesses, anxiety is disturbing as it can disrupt the normal daily function of a person (Bystritsky, 2013). Studies show that there is a high comorbidity between depression and anxiety (Thibaut, 2017). Intrusive thoughts and worries often result in a feeling of loneliness and depression. Among the general population in Asia and Europe, the prevalence rate of anxiety during the COVID-19 pandemic is $31.9 \%$ (95\% CI: 27.5-36.7) (Salari et al., 2020). Moreover, among the 12 studies assessed in China and Singapore, anxiety's prevalence rate showed $23.2 \%$ among healthcare workers during COVID-19 outbreak in a meta-analysis done by Pappa et al. (2020)

\subsubsection{Stress}

The general definition of stress can be "anything that can affect the body's homeostasis" (Schneiderman, Ironson \& Siegel, 2008). However, stress as a mental illness is defined as the feeling of overwhelm to the point of being unable to cope brought about unimaginable internal and external pressures (MHF). The meta-analysis of Salari et al. (2020) shows the prevalence rate of stress during the COVID-19 pandemic at 29.6\% (95\% CI: 24.3-35.4) among the general population in Asia and Europe.

Mental well-being has often not become a topic open for discussion. Acceptance and eradication of its stigma has been widely considered. It is only a matter of time before addressing mental health issues is considered normal.

\subsection{Covid-19 Pandemic and Mental Health}


Public health emergencies are one of the biggest stressors of the majority (Pfefferbaum \& North, 2020). It affects the health, safety, and the well-being of everyone affected by the emergency. Moreover, this results in a number of reactions related to the physical, emotional and mental state of a person. Insomnia, anxiety, and depression are just a few of the mental health illnesses that can be acquired from the fear of bereavement, isolation, and loss of income during the pandemic, according to the World Health Organization. The stress caused by the outbreak has worsened the mental health illnesses of the population (Center for Disease and Control, 2020). The psychological reaction of a person to the Covid-19 pandemic varies from the panic behavior of the people to their feeling of hopelessness due to the isolation needs to prevent the spreading of the disease (Serafini et.al., 2020). Most of the research done to evaluate the mental state of the population in the pandemic have led to a conclusion that it has negatively affected the mental being of the majority.

\section{Mental health in the workplace in normal setting}

The World Health Organization (2019) stated that work is good for the mental health of the person until the working environment becomes problematic and negative in any aspect. Negative working environment can cause physical, emotional, and mental problems. Mental health problems according to the Center for Disease Control and Prevention can affect an employee's performance in terms of job performance, productivity, engagement, communication, and daily physical capabilities.

According to Memish, Martin, Bartlett, Dawkins, and Sanderson (2017), most problems that occur in the workplace can affect the production of quality service. These are due to factors that involve the well-being of the worker, including their mental health.

Poor psychosocial work environments, such as those with low psychological support and high demands, can be harmful to the mental health of workers. (Kristman, Lowey, Fraser, Armstrong and Sawula, 2019). Mental health problems of workers are often due to the workplace. Most common reason is because the workers are not supported well by their management and their supervisors. No specific guidelines are written and followed on how to approach employees or workers' concerns regarding their mental health other than those provided by the government and the department of health. The need of the approaches such as Mental Health First Aid training is important to help improve the workplace setting (Bovopoulos, Jorm, Bond, LaMontagne, Reavley. Kelley, Kitchener, and Martin, 2016).

\subsection{Medical Frontliners}

Healthcare workers, doctors, nurses, and medical assistants are the heroes during this continuous battle against COVID-19. The long working hours under uncomfortable and stressful conditions may jeopardize their overall well-being (Bakar and Ramli, 2020). Doctors experience high levels of work stress even under normal circumstances according to Galbraith, Boyda, McFeeters and Hassan (2020). The addition of the healthcare staff mental health support process is needed to help medical frontliners in attending to their own health and their patients. The burnout syndrome of the healthcare professionals is not even new according to Bridgeman (P.), Bridgeman (M.B.) and Barone (2018). The pressure of the workplace is already contributing a lot to the stress on the mental health of the medical workers when there are still other factors to consider other than pressure. 
With not just the lives of the medical professionals on the line, once their mental health is negatively affected, it has already come to a lot of professionals' attentions the need to take the issue seriously. The medical setting contributes the most in the mental health issues encountered by their employees. The leaders of the organizations must be the spearhead in fixing the problem of the current situation. There is even a need to do more research on how to solve the ongoing problems related to the huge negative effect of the workplace to the medical workers (Cocker and Joss, 2016).

\subsection{Other Professionals}

According to Sasaki, Kuroda, Tsuno and Kawakami (2020), taking measures in the workplace in order to prevent workers from acquiring any mental health illnesses during the pandemic is very effective since the workplace itself can cause a lot of strain to the mental health of a person. Overworking is also a huge factor and the most acknowledged source of mental health problems in workers (Sachiko, 2016).

The issue about the mental health of workers in their workplace has been noted and taken into consideration already according to data. Aside from it affects the productivity of the employees, it also affects their daily and personal lives. A lot of initiatives have been done to end the stigma of mental health and to ensure that workplaces do not affect the mental health of the people (Dobson, Szeto, Knaak, Kruoa, Kirsh, Luong, Mclead and Pietrus, 2018).

\section{Factors that affect the Mental Health of the Frontliners}

\subsection{Sociodemographic Factors}

According to Campos, et. Al (2020), in terms of sociodemographic factors, the risk factor for the progression of anxiety, depression, post-traumatic stress disorder, and burnout are all associated with age. Moreover, social isolation or rejection has a great impact on the furtherance or development of posttraumatic stress disorder, stress, anxiety, and depression. Also, lack of family and cohort stability and support are correlated with burnout. Likewise, stigmatization and social rejection were also identified as risk factors for stress progression. The given interrelationships and correlations have their respective interventions that can be further analyzed and implemented eventually in order to properly address these issues. However, there is no evidence for the interventions that utilized experimental designs.

In tackling interventions, according to Angelaina, et. al (2015), health workers could be thoroughly trained to employ relaxation techniques and stress management strategies. Additionally, among the participants involved in this study, the existence of health complications also seemed to play a major role, which are exhibited by participants who did not report any health issues scored higher in positive approach and subscales. These findings are related to the preference of self-treatment which are observed among 80 $84 \%$ of male participants and $72-74 \%$ of female participants.

\subsection{Occupation}

The subsistence of various parameters that contribute to the wide progression of physical and mental well-being issues have been noticed and observed in the healthcare setting. The repercussions of critical and emergency periods have been determined and evaluated by Campos, et. Al (2020), the study is 
designed to analyze the impact of providing health service in times of health crises caused by emergency situations on mental health. Moreover, it is directed towards the identification of factors which are heavily associated with the worst impacts. Also, the study was able to evaluate and assess the possible and accessible evidence regarding certain interventions to reduce such consequences.

Wide scope interpretations through pooling different studies from MEDLINE, Embase, and PsycINFO have resulted to a pooled prevalence that has expounded significant occurrences including higher percentage for the acute stress disorder (40\%), anxiety (30\%), burnout $(28 \%)$, depression (24\%), and posttraumatic stress disorder (13\%). The researchers have described and identified several factors linked to the possibility of developing problems on mental health, which include social factors such as stigmatization and lack of support in social aspect, sociodemographic condition, and job-related determinants including engagements in high-risk surroundings. Delving deeper, the descriptions of high-risk areas differ among the published papers, however it typically involved direct and continuous contact with infected individuals which can be either providing service and care or being responsible for regular disinfection and cleaning.

Similarly, there is a higher perception of risk and threat that are related or associated with a higher prevalence regarding various mental health issues involving anxiety, depression, and post-traumatic stress disorder. Furthermore, inadequate specialized training was a major risk factor for developing anxiety, burnout, and post-traumatic stress disorder. Additionally, nurses have a high probability of developing mental health issues including post-traumatic stress disorder. Similarly, resident pulmonologists were considered at higher risk of experiencing clinical depression. Various risk factors associated with the development of post-traumatic stress disorder are job stress and less job experience. There is an increased risk of developing burnout in an environment with lower levels of organization support. These presented factors can greatly aid the furtherance and construction of methods in gathering data from a certain location.

Some of the most major factors are confidentiality and stigma which the healthcare professionals do not readily seek an appropriate mental health treatment from qualified professionals. The researchers have recommended having an open dialogue about mental illness in order to have an expounded and comprehensive knowledge about their views and perceptions as part of the healthcare workforce, which might contribute to the furtherance of effective interventions. As included in the study conducted by Dweik, et. al. (2016), female doctors have worse indicators of mental and physical health compared with other professional women. The researchers have fixated on the workload, mental health, and burnout of female physicians which resulted in no significant differences in terms of the rates of depressive symptoms and suicidal thoughts, however there is an increased prevalence of sleep disorders. Additionally, the number of workplaces, intensive role conflict, and frequency of work-related stressful situations was associated with decreased personal accomplishment and sleep disorders.

\subsection{Income}

Relating to the study of Dweik, et. al (2016), other researchers including Dzay, et. al (2019), had focused on the factors and prevalence that are associated with poor mental health among healthcare professionals in low-and lower-middle income countries. The healthy and productive healthcare workforce is the center of an efficiently functioning healthcare system; however, healthcare professionals are at increased risk in terms of poor psychological well-being which are mainly due to their strenuous work demands. In analyzing the prevalence of mental health care issues among healthcare professionals in lowand lower-middle-income countries and determining the factors that are associated with positive or poor 
mental health. The review by Dzay, et. al (2019), aims to have a synthesis of all available information for health system managers and policy makers which also highlight the gaps in identifying other possible parameters.

\subsection{Department}

As being elucidated in a study conducted by Andres, et. al (2018), presenteeism is a usual manner of conducting oneself in which a particular individual is physically existent at work but has inefficient performance because of different factors including illness. Nurses as well as medical doctors have higher probability and have more likelihood to manifest or show this particular issue than other professionals which can result in diminished health of staff, potentially increased indirect presenteeism-related consequences other than absenteeism and reduced in terms of team productivity. The systematic review by Andres, et. al (2018), emphasized the determination of instruments in identifying presenteeism and its associated outcomes, assessing theoretical frameworks related to the study, and evaluating the correlation between, presenteeism, and its associated exposures and outcomes, and other consequences including economical cost and interventions that are designed in alleviating presenteeism among hospital nurses and doctors.

As presented by Andres, et. al (2018), there are associations between presenteeism and exposures, which positively associated presenteeism with most work stressors including working with public sector, academia, having a paid leave policy, hours worked, and days of absences due to illness. However, presenteeism has no relationship with the setting, ethnicity, marital status, full-time employment, permanent employment contracts, or shift-work schedule. However, presenteeism is significantly related to most healthcare employee health exposures including acute or chronic disease, genera; health symptoms, and poor overall health condition. This study can aid in improving a more systemized multidimensional presenteeism exposures and other output instruments in order to progress cost-effective workplace suggestions regarding interventions that aim for the maintenance and sustainability of the healthcare workforce. However, there are generalizability and heterogeneity of results which are caused by limited cohort, economic valuation publications, and interventions.

Expounded in the study conducted by Kumar (2016), healthcare professionals are constantly directed to high levels of burnout and are commonly exposed to experiencing depression. Healthcare professionals that are encountering burnouts are usually noted to be at a higher risk of creating poor management and decisioning capability, displaying unprofessional attitude towards patients and colleagues, and making more medical errors. Burnout among healthcare professionals increases the probability of experiencing anxiety, depression, fatigue, sleep disturbances, alcohol and drug misuse, and premature retirement. Additionally, the extent of burnout may differ depending on the healthcare department or setting, specialization, and changes in the work environment. By the virtue of healthcare professionals' work, they are often directed to plenty of emotions such as a facing patients in emergency situations, feelings of inabilities in terms of certain illnesses and associated grief and fear, losses, a sense of frustration and failure when there is a disease progression of the patient's illness and facing various uncertainties in the clinical practice.

Kumar (2016) stated that medical doctors are commonly encountering stressors from situations and emotions, which usually arise beyond the patient-doctor relationship. Delving deeper, the healthcare professionals, including doctors, must perform in an increasingly unforgiving and litigious settings, legal 
requirements that are continuously imposed, which are changing, novel medical insights that are constantly and rapidly advancing on a daily basis, the limited resources in terms of healthcare resources in most countries which are explained by the World Medical Association. Kumar (2016), also emphasized about the risk factors of burnout among doctors which are static in nature or difficult to address through the utilization of intervention strategies. The researcher has recommended three different levels of change in order to lessen these risks, including modification of organization structure and processes related to twork, improvement of the fit between particular organization and individual doctor through different professional development programs to have better adaptation when there are changes or alterations on work protocols, and actions in individual-level for the reduction of stress and lessening the occurrence regarding poor health symptoms which can be addressed through effective and efficient coping, and promoting a healthy environment and behaviors. Burnout among healthcare professionals is a global phenomenon and once it has set in, there is limited indication that supports practicability and benefits of different modalities including cognitive behavioral therapy, music, relaxation, or creation of a positive work setting. However, prevention presents a more effective approach and is more beneficial than treatment in terms of burnout.

Healthcare professionals, based on the study emphasized by Kumar (2016), $80 \%$ of medical doctors endured a range of moderate to severe emotional exhaustion, $61 \%$ encountered a moderate to severe depersonalization, and $44 \%$ of the healthcare workforce suffer from moderate to low feelings of personal achievement. In specialization as a factor, there are high prevalence of burnout in urology which accounts for $63.6 \%$, rehabilitation and physical medicine $(63.3 \%)$, while family medicine has a prevalence of $63.0 \%$, radiology $(61.4 \%)$, orthopedic surgery $(59.6 \%)$, dermatology $(56.5 \%)$, subspecialties in general surgery $(52.7 \%)$, pathology $(52.5 \%)$, and general pediatrics $(46.3 \%)$. These various disciplines account for different environmental stressors which resulted in higher prevalence. Also, demographic determinants may facilitate an increased risk for burnout which include female gender, young age, negative marital status, long working hours, and low levels of work fulfillment and satisfaction.

According to Kumar (2016), there are proofs to suggest participating in a mindful communication program with sustained and short-term improvements in burnout among healthcare professionals. It is a study that analyzed the impact of an comprehensive educational program which encompasses an 8-week intensive aspect( 2.5 hours per week, 7 hours retreat), and a subsequent ten-month maintenance phase (2.5 hours per month) in instructing self-awareness, communication, , and mindfulness found advancements in mental well-being to be associated with considerable growth in all the three dimension of the burnout occurrence which are emotional fatigue, depersonalization, and personal accomplishment.

\subsection{Length of Service}

Physician trainee mental health has been accentuated in the academic literature, which suggests an expanding and growing interest in the challenges that are constantly encountered by physicians and its repercussions. As stated in the study conducted by Baker and Sen (2016), medical trainees have constantly demonstrated higher psychological distress. Factors that contribute to psychological distress include financial burdens, mistreatment, and developing professional cynicism. There are negative impacts that are associated during residency which includes long hours, debt, overnight shifts, dissatisfaction in terms of their lifestyle, and lack of autonomy. In addressing these factors, implementing innovative and evidencebased interventions could help among medical schools and residency programs which can prepare trainees in becoming skilled physicians, through this, they can preserve their mental health throughout the course of their profession. As stated by Kumar (2016), there are four main facets of physical stability and 
resilience such as perspectives and attitudes including the maintaining interest, physician role, developing self-awareness, and accepting one's personal limitations. Also, balance and prioritization which include taking effective and efficient approaches to continuing professional development and setting limits and honoring the self. Additionally, practice management style such as sound business management, using effective practice arrangements, and having good staff. Lastly, supportive relations including effective professional relationships, good communication, and positive personal relationships.

\subsection{Place of Service}

Two studies have been performed in Canada which evaluated two educational interventions to have an ample fixation towards improving the mental health of healthcare workers through increasing resilience. The researchers have conducted a cross-sectional evaluation for the determination of educational interventions that are directed towards the Healthcare workers during the SARS epidemic which includes a face-to-face training group session based on Folkman and Greer's method or model of coping, which focused on the main stressors that can have a highly association with the pandemic influenza, as well as individual and organization approaches in order to build resilience and reducing stress occurrence. There are also different modalities of learning which are courses that consist of modules including relaxation skills, knowledge-based modules, self-assessment modules through using questionnaires for the characterization of coping styles and interpersonal problems.

The relevance of this study in the current situation through directing and illustrating a broader view in terms of the probable and feasible interventions that can alleviate the occurrence of mental health issues of healthcare workers. Expounded in the study, there are very limited and finite indications regarding the overall impact of interventions in tackling mental health issues in healthcare workers, also the identified risk determinants facilitate and act as guiding light for future interventions. However, this study could help various regions in progressing in terms of developing proper interventions which are essential in maintaining high efficiency and producing accurate diagnosis and treatment. The possible outcome of the thorough determination regarding various parameters which can either aggravate or advance the mental health illness of healthcare can effectively develop an intervention which are stated comprehensively in the study conducted by Briscoe, et. al. (2018). Moreover, it is a review of the guided interventions in tackling the crucial problem of mental health in medical doctors. Nearly all the published literature to date has fixated towards the workplace interventions that aimed at increasing healthcare workers' resilience which places a responsibility for the mental well-being, however it neglects the structural and organizational contexts which can pose detrimental effects on the overall well-being of doctors. Also, this study maintains its realist review approach which focuses on the complexity and many dimensions of the problem of mental ill-health of doctors including individual, organizational, and sociocultural factors. Similarly, there are other factors that develop mental ill-health such stage in career, specialty, and various working settings.

Additionally, the cooperative workflow in terms of engagement of various authorities including policy makers, healthcare leaders, and healthcare professionals, will greatly support the furtherance of interventions and strategies in tackling mental ill-health in healthcare professionals. Based on this study, issues on mental health are prevalent across various groups of health professionals which poses a great determinant in various countries. The mental stability of the healthcare workers is a serious issue which might lead to absenteeism, presenteeism, and loss of staff. Most of the existing interventions have focused on increasing the resilience and productivity of the healthcare professionals which might have a 
detrimental effect due to neglecting the organizational factors which is also a major parameter for the overall well-being of the healthcare workforce.

Iterations are required for the efficiency of the project in terms of investigation and implementation of the interventions. As stated by Briscoe, et. Al (2018), there are five steps for this progress, including locating existing theories, searching for evidence, selecting appropriate articles, extracting, and organizing data, and synthesizing evidence and drawing conclusions from the interpreted data. The factors that must be thoroughly investigated include the increasing workload resulting from the attempt in providing higher quality of service, concern on shrinking budgets, systems of governance in clinical setting which are leading to the loss of autonomy and further erosion of given professional values, and rigidity of the organization structures and implementation of inflexible working hours.

The factors that are commonly correlated with mental ill-health and decisions to withdraw from the healthcare profession have been determined and identified as long working hours, high maintenance of regulation, excessive workload, fear of complaints and negligence claims, and increasing levels of regulation and scrutiny. Also, presenteeism in healthcare professionals may be caused by fear of repercussions in terms of their career, a fear of letting down patients and colleagues, a failure to recognize their own health needs or demands, and lack of process on clearly identifying their own vulnerabilities to illnesses. The study also presented that healthcare professionals may feel pressured by the collective norms; however, it is presently vague whether this changes at different career stages or in various specialties. Ultimately, there are five significant audiences that the researchers would want to reach and engage with the method of dissemination in terms of addressing and implementing strategies that could reduce the mental health instability occurrence among healthcare workers, which include authorities (i.e., policy makers) who can greatly facilitate change that will have a good impact to healthcare workers at a national level (group 1), healthcare leaders and employers that can reshape the organizational system and structure in which healthcare professionals work (group 2), team leaders who can configure the immediate working setting for each healthcare professional (group 3), local, regional, national groups and organizations that can give support to healthcare professionals encountering mental ill-health (group 4), and healthcare professionals who are confronting mental-ill health, as well as their family members and colleagues.

\section{Research Methods}

\subsection{Research Design}

The objectives of the study were achieved using a descriptive survey answered by medical frontliners, specifically physicians, nurses, and medical technologists who are actively working in a public or private hospital, other medical facilities/COVID-19 facilities in Metro Manila who are in duty before and during the COVID-19 pandemic. To allow the researchers to measure the outcomes of the answers of the participants, a descriptive research design was utilized in this study.

Quantitative results were obtained with the use of adopted questionnaires. DASS or the Depression, Anxiety, Stress scale, and the IES-COVID19 or the Impact of Event Scale with Modifications for COVID-19 served as the tools for researchers to gather data.

\subsection{Subjects and Study Site}


The respondents of the survey included physicians, nurses, and medical technologists who are actively working in a public or private hospital, other medical facilities/COVID-19 facilities within Metro Manila before and during the COVID-19 outbreak. Consent was obtained from the said participants. Therefore, the participants were allowed to withdraw from the study at any given time.

The researchers obtained 70 responses from the medical frontliners, specifically physicians, nurses, nursing assistants, respiratory therapists and medical technologists who are working on private or public hospitals or laboratories in Metro Manila through an online survey that was deployed through Google Forms.

The study was conducted within the vicinity of Metro Manila. A convenience sampling technique was employed to determine the individuals that served as the subject of the study. This technique will be used as given the circumstance during this study; the researchers only have limited resources as well as options for the data gathering procedure. The most feasible option is through an online platform.

\subsubsection{Inclusion Criteria}

- Physicians that are actively working before and during the COVID-19 pandemic.

- Nurses that are actively working before and during the COVID-19 pandemic.

- Medical technologists that are actively working before and during the COVID-19 pandemic.

- Physicians, nurses, and medical technologists that are between the age of 21 and 59.

- Physicians, nurses, and medical technologists that are working in a private or public hospital or any medical facilities.

- Physicians, nurses, and medical technologists that are working in Metro Manila, specifically Caloocan, Malabon, Valenzuela, Quezon City, Marikina, Pasig, Taguig, Manila, Mandaluyong, San Juan, Pasay, Las Piñas, and Muntinlupa.

\subsubsection{Exclusion Criteria}

- Medical frontliners who are only working in administrative positions.

- Medical frontliners actively participating in telemedicine only and are not physically exposed to hospital/ COVID-19-related facilities settings.

- Medical frontliners other than physicians, nurses, or medical technologists.

- Medical frontliners working in the cities of Navotas, Paranaque, Makati, and Pateros.

\subsection{Data Measure/Instrumentation}

In this study, the data was gathered through adopted questionnaires. First, a questionnaire that will determine the participants' demographic profile was utilized. Information regarding their name, age, gender, civil status, occupation, length of service, place of service, and the name of the hospital or facility they work for were acquired. The name and hospital or facility they work for were not disclosed and was collected only for the purpose of verification.

The Depression Anxiety and Stress Scales (DASS-21), which is utilized to study the symptoms of internalizing disorders of psychopathology that further analyzes symptoms of depression, anxiety, and 
stress is included in the second part. Moreover, it is a 4-point Likert scale from "not at all or never applicable" (0) to "definitely" or "very often applicable" (3). The obtained score is proportional to the degree of depression, anxiety, and stress. As emphasized by De Beurs, et. al. (2001), it has been determined to be consistent internally, $0.85 \leq$ Cronbach's alpha $\leq 0.91$, test-retest reliability, $0.74 \leq \mathrm{r} \leq$ 0.85 , and demonstrates enough validity in a Dutch sample involving first-year university students, which can be comparable to the given sample size. The questionnaire and thorough instructions for employing DASS-21 are included in the Appendix C.

Another questionnaire to be employed is the Impact of Event Scale with Modifications for COVID-19 (IES-COVID19). This questionnaire is an adaptation of the same Impact of Event Scale but in Dutch version (Brom \& Kleber, 1985), which was modified to be adapted and specifically applied to the situation. It is a four-point scale and 15-item questionnaire ranging from zero which indicates "not at all", one (1) for "seldom", three (3) for" sometimes", and five (5) for "often". The sum of the ratings will be calculated and interpreted. The questionnaire and the complete instructions for IES-COVID19 are included in the Appendix D. Specifically, items "1", "4", "5", "6", "10", "11", and "14 "are part of Intrusion subscale, while items "2", “3", "7", "8", “9", "12", "13", and "15" concern the Avoidance subscale. Higher scores imply a higher psychological impact of the condition regarding COVID-19.

\subsection{Data Gathering Procedure}

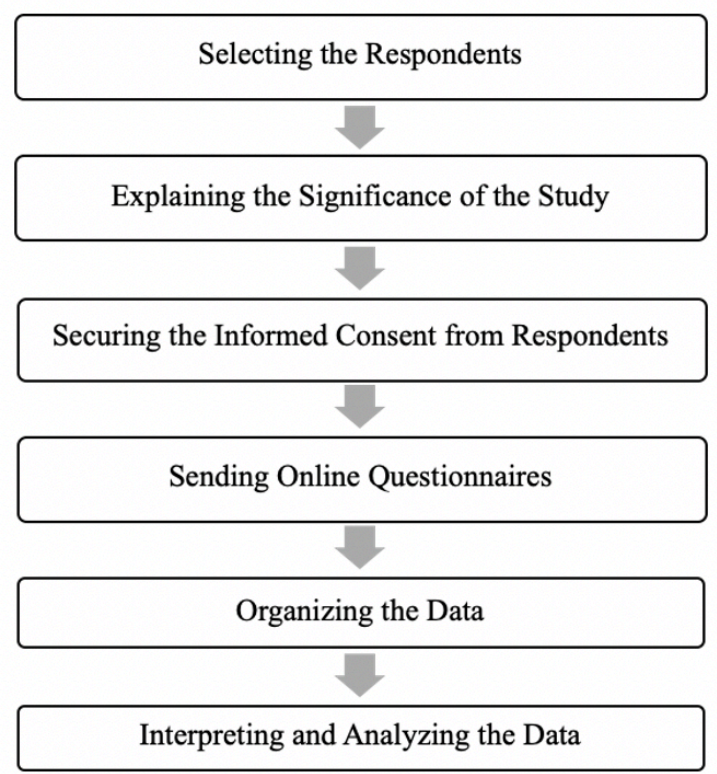

Figure 3.1 Data Gathering Flow Chart of the Study: Impact of the Covid-19 Pandemic on Mental Health Among Frontliners Working in Metro Manila

\subsubsection{Data Gathering Procedure}

The researchers selected the respondents that best fit the requirements needed in answering the questionnaire by contacting different medical frontliners through online platforms. Primarily, the focus of this study are the Medical Frontliners situated in Metro Manila, anywhere in its 16 cities. Due to the current occurrences while conducting this study, the determination of participants was 
done through the utilization of a convenience sampling method wherein the respondents came from any medical institutions and health facilities within the cities of Caloocan, Malabon, Valenzuela, Quezon City, Marikina, Pasig, Taguig, Manila, Mandaluyong, San Juan, Pasay, Las Piñas, and Muntinlupa city only. The population sample is based on WHO's 2017 data of Philippines' medical professional workers based on NCR. The total population is 35012. The margin of error used to compute the sample is $10 \%$ while the confidence level is at $90 \%$. Thus, 70 respondents were selected. Additionally, there were contact persons for the dissemination of the adopted questionnaires.

\subsubsection{Explanation of the Significance of the Study}

Before securing informed consent from respondents, the researchers provided a brief explanation on the significance of the study including the nature and purpose of the study. This will provide knowledge and understanding regarding the importance of the participation of the respondents in obtaining data for the study.

\subsubsection{Secure Informed Consent from Respondents}

After giving the significance of the study, the researchers secured an informed consent from the respondents which includes the terms and conditions and requirements in answering the online questionnaire. This served as a proof that the respondents voluntarily answered the questionnaires.

\subsubsection{Sending of Online Questionnaires}

Once a secured consent was obtained, the researcher sent the online questionnaires to the respondents through google forms via email. The participants answered two questionnaires: one for their demographic profile and the Depression, Anxiety and Stress Scale-21 (1DASS-21), a 21-item questionnaire composed of three sets of self-report scales. Since the participants were required to answer the DASS-21 twice, the total number of questions they answered is 42 . This is exclusive of the demographic profile. It will take them approximately 15-20 minutes to complete the survey.

\subsubsection{Organization of Data}

After the respondents completed answering the questionnaires, the researchers organized the data obtained in tabulated form and was sent to the assigned statistician for analysis.

\subsection{Ethical Considerations}

In this study, the researchers assessed the impact of COVID-19 pandemic on the mental health of medical frontliners working in Metro Manila. The researchers are expected to gather demographic profiles of medical frontliners, identify factors affecting their mental health, determine the impact of COVID-19 in their mental health and identify their needs with regards to their mental health. The researchers ensure that the participants of the study were given enough knowledge and background on the purpose of this study. Furthermore, consent forms were distributed to the participants to uphold their right to informed consent. The researchers guarantee that no coercion and manipulation of data will be done in any part of the study and that participants have the right to withdraw from participating in the study as they see fit. In addition to that, the researchers assure that every data collected from the participants will be treated with confidentiality and will only be used for the intended purpose of the study. Data from this research is kept 
under lock and key and reported only as a collective combined total. The identities and answers of the participants remained confidential through coding measures. There will be a specific code (P-001 to P300) which corresponds to specific data collected from participants. Participants were given acknowledgement for their participation in accomplishing the given study. In cases where there is discomfort when answering questions pertaining to mental health, participants could exercise their right to withdraw as previously mentioned. Ethical review was done through the Ethics Review Committee of the University of Santo Tomas to ensure that the respondents would not be harmed in any way throughout the study. The researchers only proceeded in gathering data once an ethical review was approved by the committee. Lastly, the course of this study would always observe transparency and honesty. The consent form is included in Appendix E.

\subsection{Data Analysis}

All data gathered were analyzed quantitatively. Descriptive statistical analysis has been performed on the sample group to obtain a clear understanding of the population, wherein the demographic profile results were first determined and assessed. Through the utilization of adopted questionnaires, specifically, DASS-21 and IES-COVID19 (Appendix C and D, respectively), the researchers, with the help of statisticians, have analyzed the data results in a descriptive approach through the "Statistical Package for the Social Sciences" (SPSS) Software. Delving deeper, the demographic profile of respondents has been evaluated by calculating the frequency and percentage, which involve age, gender, civil status, occupation, and length of service. In the determination of significant differences ( $p$ value) between various demographic profiles in terms of their depression, anxiety, and stress in two points in time (i.e., before and during pandemic), the T-test and One-Way Analysis of Variance (One-Way ANOVA) has been utilized based on DASS-21 responses, wherein the former has been utilized only when the question has two choices or groups (i.e., gender and civil status), while the latter has been used when the question has more than two choices (i.e., occupation, age group, and length of service). In ANOVA, mean and standard deviation were used to identify which groups are deviating from others. Through this, the researchers were able to evaluate if a particular demographic profile is a factor in Depression, Anxiety, and Stress in two points in time. In assessing the mental health status of medical frontliners during the prepandemic and pandemic, it has been evaluated through calculating the frequency or count of total scores, or cross-tabulation as stated in the DASS-21 procedures. Ultimately, to review the impact of the COVID19 pandemic on mental health among medical frontliners, the researchers have utilized a regression approach wherein the COVID-19 pandemic is the independent variable, while the Depression, Anxiety, and Stress Scale is the dependent variable. It involves the p-value to evaluate the significance of Depression, Anxiety, and Stress. Also, a loading (beta) factor, which multiplies the score to quantitatively determine the impact of the COVID-19 pandemic in terms of Depression, Anxiety, and Stress, which can further evaluate which among the three has the greatest impact on the mental health of the respondents. Furthermore, the researchers consulted a psychiatrist (DASS 21 \& IES COVID-19) to ensure the credibility of the results obtained. The certification can be seen in Appendix G.

\section{Results and Discussion}

\subsection{Results}

Table 1. Demographic Profile of the Respondents 


\begin{tabular}{|c|c|c|c|}
\hline Variable & & $\mathrm{n}=70$ & $\%$ \\
\hline \multirow[t]{4}{*}{ Age } & $21-30$ & 34 & 48.6 \\
\hline & $31-40$ & 20 & 28.6 \\
\hline & $41-50$ & 8 & 11.4 \\
\hline & $51-59$ & 8 & 11.4 \\
\hline \multirow[t]{2}{*}{ Gender } & Male & 30 & 42.9 \\
\hline & Female & 40 & 57.1 \\
\hline \multirow[t]{2}{*}{ Civil Status } & Single & 57 & 81.4 \\
\hline & Married & 13 & 16.6 \\
\hline \multirow[t]{5}{*}{ Occupation } & Physician & 20 & 28.6 \\
\hline & Nurse & 33 & 47.1 \\
\hline & Med Tech & 15 & 21.4 \\
\hline & Nursing Asst & 1 & 1.4 \\
\hline & Respiratory Th & 1 & 1.4 \\
\hline \multirow{4}{*}{$\begin{array}{l}\text { Length of } \\
\text { Service }\end{array}$} & $<5 \mathrm{yrs}$ & 41 & 58.6 \\
\hline & & & \\
\hline & $5-10 \mathrm{yrs}$ & 9 & 12.9 \\
\hline & $>=10 \mathrm{yrs}$ & 20 & 28.6 \\
\hline \multirow{11}{*}{$\begin{array}{l}\text { Place of } \\
\text { Service }\end{array}$} & Caloocan & 1 & 1.4 \\
\hline & & & \\
\hline & Las Piñas & 1 & 1.4 \\
\hline & Malabon & 1 & 1.4 \\
\hline & Mandaluyong & 6 & 8.6 \\
\hline & Manila & 19 & 27.1 \\
\hline & Marikina & 3 & 4.3 \\
\hline & Muntinlupa & 1 & 1.4 \\
\hline & Pasay & 1 & 1.4 \\
\hline & Pasig & 12 & 17.1 \\
\hline & Quezon City & 19 & 27.1 \\
\hline
\end{tabular}




\begin{tabular}{ccc}
\hline San Juan & 2 & 2.9 \\
Taguig & 1 & 1.4 \\
Valenzuela & 3 & 4.3
\end{tabular}

Table 1 presents the frequency and the percentage distribution of the respondents' demographic profile. The specified demographic profiles are the age group, gender, civil status, specific occupation, the length of service, and the place of service. Based on the collected data, $48.6 \%$ of the respondents are under the age bracket of 21 years old to 30 years old and $57.1 \%$ of the whole population are females. Also, $81.4 \%$ of the respondents are single. The respondents are medical frontliners, specifically physicians, medical technologists, nurses, nursing assistants and respiratory therapists. The results showed that $47.1 \%$ of the respondents are nurses. 58.6\% of the respondents have been working for $(<5 \mathrm{yrs})$ less than five years as a medical professional. The table also shows that among the 14 cities in Metro Manila, Quezon City and Manila has the highest frequency of $27.1 \%$ individually.

Table 2. Depression, Anxiety, and Stress between Males and Females (Before Pandemic)

\begin{tabular}{llcccc}
\hline Before Pandemic & Mean & $\begin{array}{c}\text { Std. } \\
\text { Deviation }\end{array}$ & $\mathrm{t}$ & $\begin{array}{c}\text { Sig. (2- } \\
\text { tailed) }\end{array}$ \\
\hline $\begin{array}{l}\text { Depres } \\
\text { sion }\end{array}$ & Male & 3.67 & 4.428 & -.604 & 0.548 \\
& Female & 4.26 & 3.968 & & \\
$\begin{array}{l}\text { Anxiet } \\
\text { y }\end{array}$ & Male & 3.63 & 3.926 & -.503 & 0.617 \\
& Female & 4.10 & 3.781 & & \\
Stress & Male & 4.23 & 4.305 & -.192 & 0.848 \\
& & 4.43 & 4.006 & & \\
\hline
\end{tabular}

This table displays the mean, standard deviation, and the p-value of the obtained responses according to gender. It demonstrates if there is a significant difference between males and females in terms of Depression, Anxiety, and Stress before the pandemic by using the independent t-test. It shows that there is no significant difference ( $\mathrm{p}$-value $>0.05$ ) between males and females in terms of Depression, Anxiety, and Stress before the pandemic.

Table 3. Depression, Anxiety, and Stress between Males and Females (During Pandemic)

\begin{tabular}{lccccc}
\hline During Pandemic & Mean & $\begin{array}{c}\text { Std. } \\
\text { Deviation }\end{array}$ & $\mathrm{t}$ & $\begin{array}{c}\text { Sig. (2- } \\
\text { tailed) }\end{array}$ \\
\hline $\begin{array}{l}\text { Depressi } \\
\text { on }\end{array}$ & Male & 4.63 & 4.484 & -1.165 & 0.248 \\
& Female & 5.90 & 4.517 & & \\
Anxiety & Male & 5.03 & 4.156 & -.427 & 0.671 \\
\hline
\end{tabular}




\begin{tabular}{llllll}
\hline & Female & 5.48 & 4.379 & & \\
\multirow{2}{*}{ Stress } & Male & 5.77 & 4.454 & -.267 & 0.790 \\
& Female & 6.05 & 4.344 & & \\
\hline
\end{tabular}

This table displays the mean, standard deviation, and the p-value of the obtained responses according to gender. It demonstrates if there is a significant difference between males and females in terms of Depression, Anxiety, and Stress during the pandemic by using the independent t-test. It shows that there is no significant difference ( $p$-value $>0.05$ ) between males and females in terms of Depression, Anxiety, and Stress during the pandemic.

Table 4. Depression, Anxiety, and Stress between those Single and Married (Before Pandemic)

\begin{tabular}{|c|c|c|c|c|c|}
\hline \multicolumn{2}{|c|}{ Before Pandemic } & \multirow{2}{*}{$\begin{array}{c}\text { Mean } \\
4.02\end{array}$} & \multirow{2}{*}{$\begin{array}{c}\begin{array}{c}\text { Std. } \\
\text { Deviation }\end{array} \\
4.4328\end{array}$} & \multirow{2}{*}{$\frac{\mathrm{t}}{.014}$} & \multirow{2}{*}{$\begin{array}{c}\text { Sig. (2- } \\
\text { tailed) } \\
0.989\end{array}$} \\
\hline Depression & Single & & & & \\
\hline & Married & 4.00 & 3.416 & & \\
\hline \multirow[t]{2}{*}{ Anxiety } & Single & 4.12 & 3.937 & 1.021 & 0.311 \\
\hline & Married & 2.92 & 3.226 & & \\
\hline \multirow[t]{2}{*}{ Stress } & Single & 4.42 & 4.309 & .331 & 0.741 \\
\hline & Married & 4.00 & 3.186 & & \\
\hline
\end{tabular}

This table displays the mean, standard deviation, and the p-value of the obtained responses according to their civil status. It demonstrates if there is a significant difference between respondents who are single and those who are married in terms of Depression, Anxiety, and Stress before the pandemic by using the independent $t$-test. It shows that there is no significant difference ( $p$-value $>0.05$ ) between those single and married in terms of Depression, Anxiety, and Stress before the pandemic.

Table 5. Depression, Anxiety, and Stress between those Single and Married (During Pandemic)

\begin{tabular}{|c|c|c|c|c|c|}
\hline \multicolumn{2}{|c|}{ During Pandemic } & \multirow{2}{*}{$\begin{array}{c}\text { Mean } \\
5.42\end{array}$} & \multirow{2}{*}{$\begin{array}{c}\begin{array}{c}\text { Std. } \\
\text { Deviation }\end{array} \\
4.698\end{array}$} & \multirow{2}{*}{$\begin{array}{c}\mathrm{t} \\
.246\end{array}$} & \multirow{2}{*}{$\begin{array}{c}\text { Sig. (2-tailed) } \\
0.806\end{array}$} \\
\hline Depression & Single & & & & \\
\hline \multirow{3}{*}{ Anxiety } & Married & 5.908 & 4.752 & \multirow{3}{*}{.482} & \multirow{3}{*}{0.632} \\
\hline & Single & 5.40 & 4.301 & & \\
\hline & Married & 4.77 & 4.206 & & \\
\hline Stress & Single & 5.91 & 4.572 & -.065 & 0.948 \\
\hline
\end{tabular}


$\begin{array}{lll}\text { Married } & 6.00 & 3.440\end{array}$

This table displays the mean, standard deviation, and the p-value of the obtained responses according to their civil status. It demonstrates if there is a significant difference between respondents who are married to those who are not in terms of Depression, Anxiety, and Stress during the pandemic by using the independent $\mathrm{t}$-test. It shows that there is no significant difference ( $\mathrm{p}$-value $>0.05$ ) between those single and married in terms of Depression, Anxiety, and Stress during the pandemic.

Table 6. Depression, Anxiety, and Stress according to Age Groups (Before Pandemic)

\begin{tabular}{|c|c|c|c|c|c|}
\hline Before Pandemic & Age & Mean & $\begin{array}{c}\text { Std. } \\
\text { Deviation }\end{array}$ & $\mathrm{F}$ & Sig. \\
\hline \multirow[t]{4}{*}{ Depression } & $21-30$ & 4.50 & 4.308 & 1.082 & 0.363 \\
\hline & $31-40$ & 4.50 & 4.286 & & \\
\hline & $41-50$ & 2.38 & 3.662 & & \\
\hline & $51-59$ & 2.38 & 3.335 & & \\
\hline \multirow[t]{4}{*}{ Anxiety } & $21-30$ & 4.79 & 4.176 & 2.891 & 0.042 \\
\hline & $31-40$ & 4.25 & 3.522 & & \\
\hline & $41-50$ & 1.50 & 2.507 & & \\
\hline & $51-59$ & 1.63 & 2.264 & & \\
\hline \multirow[t]{4}{*}{ Stress } & $21-30$ & 5.12 & 4.643 & 2.149 & 0.102 \\
\hline & $31-40$ & 4.80 & 3.563 & & \\
\hline & $41-50$ & 2.00 & 3.117 & & \\
\hline & $51-59$ & 2.25 & 2.375 & & \\
\hline
\end{tabular}

Table 7. Depression, Anxiety, and Stress according to Age Groups (During Pandemic)

\begin{tabular}{lrcccc}
\hline \multicolumn{2}{l}{$\begin{array}{l}\text { During Pandemic. } \\
\text { Age }\end{array}$} & Mean & Std. Deviation & F & Sig. \\
\hline Depression & $21-30$ & 6.35 & 5.157 & 1.375 & 0.258 \\
& $31-40$ & 4.80 & 3.901 & & \\
& $41-50$ & 3.13 & 3.399 & \\
\hline
\end{tabular}




\begin{tabular}{lccccc}
\hline & $51-59$ & 4.75 & 3.284 & & \\
Anxiety & $21-30$ & 6.38 & 4.639 & 2.258 & 0.090 \\
& $31-40$ & 4.90 & 3.227 & & \\
& $41-50$ & 2.38 & 3.378 & & \\
& $51-59$ & 4.50 & 4.598 & & \\
Stress & $21-30$ & 7.21 & 4.829 & 3.022 & 0.036 \\
& $31-40$ & 5.60 & 3.283 & & \\
& $41-50$ & 2.63 & 3.335 & & \\
\hline
\end{tabular}

Tables 6 and 7 display the mean, standard deviation, and the p-value of the obtained responses according to their age groups. It demonstrates if there is a significant difference among those respondents aged 21-30, 31-40, 41-50, and 51-59 in terms of Depression, Anxiety, and Stress before and during the pandemic, respectively. Analysis was done by using ANOVA. In terms of Anxiety before and Stress during the COVID-19 pandemic, it shows that there is a significant difference (p-value <0.05) between the age groups. Other than that, there is no significant difference (p-value $>0.05$ ) between the age groups in terms of Depression and Stress before the pandemic, and Depression and Anxiety during the pandemic.

Table 8. Depression, Anxiety, and Stress according to Occupation (Before Pandemic)

\begin{tabular}{|c|c|c|c|c|c|}
\hline \multicolumn{2}{|c|}{ Before Pandemic } & \multirow{2}{*}{$\begin{array}{c}\text { Mean } \\
2.80\end{array}$} & \multirow{2}{*}{$\begin{array}{c}\begin{array}{c}\text { Std. } \\
\text { deviation }\end{array} \\
3.982\end{array}$} & \multirow{3}{*}{$\begin{array}{c}\mathrm{F} \\
1.235\end{array}$} & \multirow{3}{*}{$\begin{array}{l}\text { Sig. } \\
0.305\end{array}$} \\
\hline Depressi & Physician & & & & \\
\hline & Nurse & 4.76 & 4.388 & & \\
\hline & $\begin{array}{l}\text { Medical } \\
\text { Technologist }\end{array}$ & 4.53 & 3.662 & & \\
\hline & $\begin{array}{l}\text { Nursing } \\
\text { Assistant }\end{array}$ & 0.00 & & & \\
\hline & $\begin{array}{l}\text { Respiratory } \\
\text { Assistant }\end{array}$ & 0.00 & & & \\
\hline \multirow[t]{3}{*}{ Anxiety } & Physician & 2.20 & 3.318 & 2.115 & 0.089 \\
\hline & Nurse & 4.76 & 3.929 & & \\
\hline & $\begin{array}{l}\text { Medical } \\
\text { Technologist }\end{array}$ & 4.73 & 3.674 & & \\
\hline
\end{tabular}




\begin{tabular}{|c|c|c|c|c|c|}
\hline \multirow{7}{*}{ Stress } & $\begin{array}{l}\text { Nursing } \\
\text { Assistant }\end{array}$ & 0.00 & & \multirow{7}{*}{1.249} & \multirow{7}{*}{0.299} \\
\hline & $\begin{array}{l}\text { Respiratory } \\
\text { Assistant }\end{array}$ & 1.00 & & & \\
\hline & Physician & 3.10 & 3.432 & & \\
\hline & Nurse & 5.00 & 4.272 & & \\
\hline & $\begin{array}{l}\text { Medical } \\
\text { Technologist }\end{array}$ & 5.07 & 4.415 & & \\
\hline & $\begin{array}{l}\text { Nursing } \\
\text { Assistant }\end{array}$ & 0.00 & & & \\
\hline & $\begin{array}{l}\text { Respiratory } \\
\text { Assistant }\end{array}$ & 1.00 & & & \\
\hline
\end{tabular}

Table 9. Depression, Anxiety, and Stress according to Occupation (During Pandemic)

\begin{tabular}{|c|c|c|c|c|c|}
\hline \multicolumn{2}{|c|}{ During Pandemic } & \multirow{2}{*}{$\begin{array}{c}\text { Mean } \\
3.65\end{array}$} & \multirow{2}{*}{$\begin{array}{c}\begin{array}{c}\text { Std. } \\
\text { deviation }\end{array} \\
4.133\end{array}$} & \multirow{2}{*}{$\begin{array}{c}\mathrm{F} \\
1.687\end{array}$} & \multirow{2}{*}{$\begin{array}{l}\text { Sig. } \\
0.164\end{array}$} \\
\hline Depression & Physician & & & & \\
\hline & Nurse & 5.82 & 4.172 & & \\
\hline & $\begin{array}{l}\text { Medical } \\
\text { Technologist }\end{array}$ & 6.80 & 5.294 & & \\
\hline & $\begin{array}{l}\text { Nursing } \\
\text { Assistant }\end{array}$ & 0.00 & & & \\
\hline & $\begin{array}{l}\text { Respiratory } \\
\text { Assistant }\end{array}$ & 8.00 & & & \\
\hline \multirow[t]{5}{*}{ Anxiety } & Physician & 3.25 & 3.683 & 2.659 & 0.040 \\
\hline & Nurse & 6.12 & 4.037 & & \\
\hline & $\begin{array}{l}\text { Medical } \\
\text { Technologist }\end{array}$ & 6.73 & 4.605 & & \\
\hline & $\begin{array}{l}\text { Nursing } \\
\text { Assistant }\end{array}$ & 0.00 & & & \\
\hline & $\begin{array}{l}\text { Respiratory } \\
\text { Assistant }\end{array}$ & 2.00 & & & \\
\hline Stress & Physician & 4.65 & 3.438 & 1.320 & 0.272 \\
\hline
\end{tabular}




\begin{tabular}{|c|c|c|}
\hline Nurse & 6.27 & 4.281 \\
\hline $\begin{array}{l}\text { Medical } \\
\text { Technologist }\end{array}$ & 7.27 & 5.365 \\
\hline $\begin{array}{l}\text { Nursing } \\
\text { Assistant }\end{array}$ & 0.00 & \\
\hline $\begin{array}{l}\text { Respiratory } \\
\text { Assistant }\end{array}$ & 6.00 & \\
\hline
\end{tabular}

Table 8 and 9 shows the difference of the mean, standard deviation and p-value obtained of depression, anxiety, and stress according to occupation before and during the pandemic. Table 8 demonstrates that there is no significant difference for depression, anxiety, and stress before the pandemic. All the three factors before the pandemic show p-values that are higher than 0.05. Table 9 shows that there is a significant difference for the factor anxiety only. Anxiety has a p-value of 0.040 which is lower than 0.05 . This means that depression and stress during the pandemic does not have a significant difference.

Table 10. Depression, Anxiety, and Stress according to Length of Service (Before Pandemic)

\begin{tabular}{|c|c|c|c|c|c|}
\hline $\begin{array}{l}\text { Before } \\
\text { Pandemic }\end{array}$ & $\begin{array}{l}\text { Length } \\
\text { Service }\end{array}$ & Mean & $\begin{array}{c}\text { Std. } \\
\text { deviation }\end{array}$ & $\mathrm{F}$ & Sig. \\
\hline \multirow[t]{3}{*}{ Depression } & $<5$ years & 4.56 & 4.450 & 1.150 & 0.323 \\
\hline & 5-10 years & 4.11 & 4.622 & & \\
\hline & $>10$ years & 2.85 & 3.133 & & \\
\hline \multirow[t]{3}{*}{ Anxiety } & $<5$ years & 4.49 & 3.938 & 4.622 & 0.013 \\
\hline & 5-10 years & 5.67 & 4.500 & & \\
\hline & $>10$ years & 1.90 & 2.337 & & \\
\hline \multirow[t]{3}{*}{ Stress } & $<5$ years & 4.80 & 4.445 & 3.316 & 0.042 \\
\hline & 5-10 years & 6.22 & 4.116 & & \\
\hline & $>10$ years & 2.55 & 2.645 & & \\
\hline
\end{tabular}

This table displays the mean, standard deviation, and the p-value of the obtained responses according to their length of service. It demonstrates if there is a significant difference among those respondents who are currently employed in their institution/facility for less than 5 years, 5-10 years, and those employed for more than 10 years in terms of Depression, Anxiety, and Stress during the COVID-19 pandemic. ANOVA was used to analyze the data. Other than Anxiety and Stress before the pandemic, which show significant difference (pvalue $>0.05$ ) between the respondents' length of service, there is no significant difference among the different groups according to their length of service. 


\begin{tabular}{llcccc}
\hline $\begin{array}{l}\text { During } \\
\text { Pandemic }\end{array}$ & $\begin{array}{l}\text { Length of } \\
\text { Service }\end{array}$ & Mean & $\begin{array}{c}\text { Std. } \\
\text { deviation }\end{array}$ & F & Sig. \\
\hline Depression & $<5$ years & 5.68 & 5.012 & .641 & 0.530 \\
& $5-10$ years & 6.00 & 5.074 & & \\
& $>10$ years & 4.40 & 2.981 & & \\
Anxiety & $<5$ years & 5.73 & 4.410 & 1.888 & 0.159 \\
& $5-10$ years & 6.56 & 4.475 & & \\
& $>10$ years & 3.80 & 3.607 & & \\
Stress & $<5$ years & 6.37 & 4.619 & 1.954 & 0.150 \\
& $5-10$ years & 7.33 & 4.822 & & \\
& $>10$ years & 4.40 & 3.251 & & \\
\hline
\end{tabular}

This table displays the mean, standard deviation, and the p-value of the obtained responses according to their length of service. It demonstrates if there is a significant difference among those respondents who are currently employed in their institution/facility for less than 5 years, 5-10 years, and those employed for more than 10 years in terms of Depression, Anxiety, and Stress during the COVID-19 pandemic. ANOVA was used to analyze the data. It shows that there is no significant difference ( $\mathrm{p}$-value $>0.05$ ) among the different groups according to their length of service.

Table 12. Mental Health Status of Medical Frontliners During the Pre-Pandemic Period

\begin{tabular}{|c|c|c|c|c|c|c|}
\hline & $\begin{array}{l}\text { Depressio } \\
\mathrm{n}\end{array}$ & $\%$ & Anxiety & $\%$ & Stress & $\%$ \\
\hline Normal & 40 & 57.1 & 36 & 51.4 & 57 & 81.4 \\
\hline Mild & 11 & 15.7 & 10 & 14.4 & 5 & 7.1 \\
\hline Moderate & 14 & 20 & 12 & 17.1 & 3 & 4.3 \\
\hline Severe & 2 & 2.9 & 5 & 7.1 & 4 & 5.8 \\
\hline $\begin{array}{l}\text { Extremely } \\
\text { Severe }\end{array}$ & 3 & 4.3 & 7 & 10 & 1 & 1.4 \\
\hline Total & 70 & 100 & 70 & 100 & 70 & 100 \\
\hline
\end{tabular}


Table 13. Mental Health Status of Medical Frontliners During the Pandemic Period

\begin{tabular}{lcccccc}
\hline & Depression & $\%$ & Anxiety & $\%$ & Stress & $\%$ \\
\hline Normal & 58 & 82.9 & 48 & 68.6 & 68 & 97.1 \\
Mild & 7 & 10 & 8 & 11.4 & 2 & 2.9 \\
Moderate & 5 & 7.1 & 13 & 18.6 & 0 & 0 \\
Severe & 0 & 0 & 1 & 1.4 & 0 & 0 \\
$\begin{array}{l}\text { Extremely } \\
\text { Severe }\end{array}$ & 0 & 0 & 0 & 0 & 0 & 0 \\
& 70 & 100 & 70 & 100 & 70 & 100 \\
\hline
\end{tabular}

Tables 12 and 13 display the result of the Dass-21 questionnaire. Since this was answered by the respondents twice; one considering the pre-pandemic period and the other considering the pandemic period, tables 10 and 11 show the mental health status of the medical frontliners before and during the pandemic, respectively. The Dass-21 was scored by using a scoring template where the sum of each subscale (D for depression, A for anxiety, and $\mathrm{S}$ for stress) was recorded then multiplied by 2 . A table for interpretation was provided to determine the severity labels of the scores obtained. A copy of the questionnaire and the interpretation can be seen in Appendix C.

Table 14. Impact of the Covid-19 Pandemic on Mental Health among Medical Frontliners

\begin{tabular}{lccc}
\hline & $\beta$ & $\mathrm{t}$ & $\mathrm{p}$ \\
\hline Depression & .699 & 8.049 & .000 \\
Anxiety & .638 & 6.830 & .000 \\
Stress & .544 & 5.351 & .000 \\
\hline
\end{tabular}

The table shows that COVID-19, the independent variable of the study, has a significant impact on the mental health of medical frontliners since the p-value is less than 0.05 , which is .000 for all three factors. There are three specific factors involved namely depression, anxiety and stress. According to the result, the COVID19 pandemic has the greatest impact on depression $(\beta=.699)$, followed by anxiety $(\beta=.638)$, and the lowest is stress $(\beta=.544)$.

\subsection{Discussion}

News about an unheard-of respiratory virus has been circulating around as early as December 2019. During this time, people were unwary; unaware of what future lies ahead of them. On the 11th day of March 2020, the World Health Organization declared the COVID-19 Pandemic. SARS-CoV2 is the causative agent of the highly contagious coronavirus that can spread from person to person, with effects that vary from mild to extremely severe cases. As this is a health emergency, it has put our health workers under an unimaginable amount of pressure. The results of the survey show the degree of the impact of the COVID-19 pandemic on the mental health among medical frontliners actively working in Metro Manila. 
4.2.1 Significant Difference between the Demographic Profiles in terms of Depression, Anxiety, and Stress

Results of the survey show that there is no significant difference ( $\mathrm{p}$-value $>0.05$ ) between the demographic profiles except for Anxiety before the COVID-19 pandemic, and Stress during the pandemic when the respondents are grouped according to age and Anxiety and Stress before the pandemic when grouped according to their length of service.

In terms of Anxiety before the pandemic, the age group 21-30 had the highest mean (4.79). Likewise, in terms of stress during the pandemic, the same age group garnered the highest mean (7.21). Moreover, respondents who are employed in the same institution for 5-10 years had the highest mean in terms of Anxiety and Stress before the pandemic. The group obtained a mean of 5.67 and 6.22 for Anxiety and Stress, respectively.

4.2.2 The mental health status of medical frontliners during the pre-pandemic and the pandemic period

Based on the results from Table 10 and 11, it can be observed that the results in terms of mental health status of medical frontliners before the pandemic were normal with scores of $57.1 \%$, $51.4 \%$ and $81.4 \%$ for depression, anxiety, and stress respectively. Likewise, mental health status of medical frontliners during the pandemic were also normal with scores of $82.9 \%, 68.6 \%$ and $97.1 \%$ for depression, anxiety and stress. In conclusion, we can say that there was an increase in terms of respondents who felt "normal" during the pandemic in comparison to pre-pandemic. In addition to that, anxiety of respondents before the pandemic was higher than during the pandemic. Lastly, in terms of stress, there was also an increase in terms of respondents who felt "normal" during the pandemic as compared to before the pandemic.

\subsubsection{The impact of the Covid-19 pandemic on mental health among medical frontliners}

According to the results, the Covid-19 pandemic has an impact on the mental health of the medical frontliners. The p-value is lower than the 0.05 which means a significant difference does exist. The three factors involved were depression, anxiety and stress.

\subsubsection{Depression;}

Depression is one of the most common serious mental illnesses that affects how people act and feel according to the American Psychiatric Association (APA). The results showed that Covid19 pandemic has the highest impact on the disorder. With the $\beta=.699$, depression has higher significance than anxiety and stress.

\subsubsection{Anxiety; and}

According to the results, anxiety followed depression with $\beta=.638$ as the second highest factor the Covid-19 pandemic has an impact on. Anxiety disorders are defined by the APA as the most common mental health disorders which affects a lot of adults. 


\subsubsection{Stress}

The Covid-19 pandemic has the lowest impact on the mental health of the medical frontliners with $\beta=.544$. Stress is one of the mental health problems experienced by a lot of people according to the Mental Health Foundation and is common to people who experience problems and struggles in life. The pandemic is a factor that causes stress to medical frontliners.

\section{Summary, Conclusion, and Recommendation}

\subsection{Summary}

Novel Coronavirus (2019-NCoV) is an infectious disease that began in Wuhan, China last December 2019 and Philippines is the second leading country in terms of cases and deaths. With this, our healthcare workers face pressure and challenges brought upon by the pandemic that could affect their performance and overall well-being. They are faced with "stress, toxic cultural environment, limited number of workforces, poor job design that leads to overwork, lack of hazard pay, extended work hours, exposure to massive deaths, and fear of contracting the disease are causing mental health problems to healthcare workers" (Baron, 2020). This study revolved around the impact of COVID-19 on mental health of medical workers in Metro Manila.

This study made use of questionnaires in gathering the data of the participants. It includes the demographic profile of the participants. Necessary information was gathered such as their name, age, occupation, place of service, and the name of the hospital they worked for -- which weren't disclosed. Depression Anxiety and Stress Scales (DASS-21), a 4-point Likert scale was also utilized in order to further analyze the symptoms of depression, anxiety, and stress. Higher scores indicate higher rates of depression, anxiety, and stress. Furthermore, Impact of Event Scale with Modifications for COVID-19 (IES-COVID19) was also implemented. It is a 4-point scale and 15-item questionnaire ranging from 0 which indicates "not at all", 1 for "seldom", 3 for" sometimes", and 5 for "often". Higher scores indicate a higher psychological impact of the condition regarding COVID-19.

In the final analysis of the demographic profile of the respondents, there is no significant difference between males and females, and single and married in terms of Depression, Anxiety, and Stress before the pandemic as well as during. For the age group, it shows that there is a significant difference between the age groups. In terms of length of service, there is a significant difference in terms of anxiety and stress before the pandemic. However, there is no significant difference during the pandemic. Based on the results of DASS-21, there is a significant difference in the mental health status of the medical frontline workers during the pandemic compared to their mental health status before the pandemic but still, the majority of the respondents are normal before and during the pandemic. Lastly, based on the result of IES-COVID19, COVID-19 has an impact on the mental health of medical workers. Three factors were involved including depression, anxiety, and stress -- depression having the highest impact followed by anxiety then stress.

\subsection{Conclusion}

The result of the study shows that there is no significant difference between males and females and single and married, in terms of Depression, Anxiety and Stress before and during the pandemic. For the different age groups, it shows that there is significant difference in terms of Anxiety before the pandemic and Stress during 
the pandemic. In terms of the length of service, there is significant difference only in the anxiety and stress before the pandemic and no significant difference during the pandemic. Based on the results of DASS-21, there is an impact on the mental health status of the medical frontliners during the pandemic when compared with the mental health status before the pandemic. However, it still shows that the majority of the respondents are normal both in pre-pandemic and pandemic periods. Additionally, the result of IES-COVID19 shows that the COVID-19 pandemic has a significant impact on the mental health of medical frontliners. The greatest impact of COVID-19 can be seen in depression, followed by anxiety, and stress. Overall, the findings of the study show that pandemics have an impact on mental health of the medical frontliners. This knowledge can help in raising awareness regarding the mental health of medical frontliners and in assessing the appropriate interventions and protocols in healthcare institutions, especially during pandemic periods. Furthermore, this can be used by future researchers as a reference and supporting evidence on the effects of pandemic in the mental health of medical frontliners.

\subsection{Recommendation}

The researchers have identified various parameters that are significant in the process of interpreting the obtained data from the respondents. Specifically, increasing the target population size and monitoring the gaps in terms of demographic profiles including the age of the respondents, which are clustered or grouped, in order to have an equal distribution of responses among age groups. Delving deeper, unequal distributions in grouped parameters have a significant effect on the overall process of analyzing the data including the mean and standard deviation that have substantial effect on the determination of the significant difference among grouped data. Simultaneously, future studies should provide more specific occupation choices through given listing in order to be more particular with the exact occupation of respondents for quick grouping and assessing of data.

\section{Acknowledgements}

It is our genuine pleasure to express our gratitude to our mentor, Anna Liezle T. Pagud, RMT, MD, MPH who was very dedicated in guiding and leading her students and for patiently answering every question we had, as we completed this research.

To Assoc. Prof. Agnes Castillo, PhD, for ensuring that every part of our research is done ethically and with responsible conduct.

To Asst. Prof. Virginia R. Arceo, $\mathrm{PhD}$, for imparting her knowledge and expertise in data analysis.

To Mr. Gail S. Fernandez, for his time, effort, and patience in editing our manuscript.

To our parents, for their love, support, and understanding throughout the whole journey of completing this research.

To our classmates, 3N-MT, for always lending their hands whenever we need it and for supporting us endlessly.

To our respondents, for their trust, honesty, and cooperation. We will not be able to push through with this research without you. 


\section{References}

Agovino, T. (2020, February 28). Mental Illness and the Workplace. Retrieved October 11, 2020, from https://www.shrm.org/hrtoday/news/all-things-work/pages/mental-illness-and-the-workplace.aspx

$\begin{array}{llll}\text { American } & \text { Psychological } & \text { Association. } & \text { (n.d.). Retrieved }\end{array}$ https://www.apa.org/topics/anxiety\#: :text=Anxiety\%20is\%20an\%20emotion\%20characterized,certain $\% 20$ situations $\% 20 \mathrm{out} \% 20 \mathrm{of}$ $\% 20$ worry.

American Psychological Association. (2019). Retrieved from https://www.sciencedaily.com/releases/2019/03/190315110908.htm

Antony, M. M., Bieling, P. J., Cox, B. J., Enns, M. W., \& Swinson, R. P. (1998). Psychometric properties of the 42-item and 21-item versions of the Depression Anxiety Stress Scales in clinical groups and a community sample. Psychological Assessment, 10(2), 176-181. https://doi.org/10.1037/1040-3590.10.2.176

Bakar, A., \& Ramli, S. (2020, July 1). Psychosocial support for healthcare frontliners during COVID-19 pandemic in Malaysia. Retrieved October 11, 2020, from https://www.ncbi.nlm.nih.gov/pmc/articles/PMC7328564/ doi: 10.1016/j.ajp.2020.102272

Baker, K., \& Sen, S. (2016). Healing Medicine's Future: Prioritizing Physician Trainee Mental Health. AMA journal of ethics, 18(6), 604-613. https://doi.org/10.1001/journalofethics.2016.18.6.medu1-1606

Banal, M.A., Conaco, M.C.G., Natividad, J., \& Puyat, J. H. (2020). Depressive symptoms among young adults in the Philippines: Results from a nationwide cross-sectional survey. Journal of Affective Disorders Reports. Retrieved from https://www.researchgate.net/publication/348180930_Depressive_symptoms_among_young_adults_in_the_Philippines_Results_fro m_a_nationwide_cross-sectional_survey

Baron, G. (2020, July 21). COVID-19 wreaks havoc on healthcare workers' mental health. Retrieved September 01, 2020, from https://mb.com.ph/2020/07/21/covid-19-wreaks-havoc-on-healthcare-workers-mental-health/

Beaufort I, N, De Weert-Van Oene G, H, Buwalda V, A, J, de Leeuw J, R, J, Goudriaan A, E: The Depression, Anxiety and Stress Scale (DASS-21) as a Screener for Depression in Substance Use Disorder Inpatients: A Pilot Study. Eur Addict Res 2017;23:260-268. doi: 10.1159/000485182

Bonquin, C. (2020). Physicians: This is the last time we'll call for 'timeout' amid COVID-19 crisis. Retrieved September 01, 2020, from https://www.cnn.ph/news/2020/8/4/physicians-last-medical-timeout-covid-19-crisis.html

Bottesi G, Ghisi M, Altoè G, Conforti E, Melli G, Sica C: The Italian version of the Depression anxiety stress scales-21: factor structure and psychometric properties on community and clinical samples. Compr Psychiatry 2015; 60: 170-181. https://doi.org/10.1016/j.comppsych.2015.04.005

Bovopoulos, N., Jorm, A., Bond, K., LaMontagne, A., Reavley, N., Kelly, C., . . Martin, A. (2016, August 2). Providing mental health first aid in the workplace: A Delphi consensus study. Retrieved October 11, 2020, from https://www.ncbi.nlm.nih.gov/pmc/articles/PMC4971664/ doi: 10.1186/s40359-016-0148-X

Bridgeman, P., Bridgeman, M., \& Barone, J. (2018, February 01). Burnout syndrome among healthcare professionals. Retrieved October 11, 2020, from https://academic.oup.com/ajhp/article-abstract/75/3/147/5102013 https://doi.org/10.2146/ajhp170460

Brisco, S., Jackson M., et. al (2018). 'Care Under Pressure': A realist review of interventions to tackle doctors' mental ill-health and its impacts on the clinical workforce and patient care. BMJ Open. Retrieved October 10, 2020, from https://bmjopen.bmj.com/content/8/2/e021273. doi: 10.1136/bmjopen-2017-021273

Bystritsky, A., Khalsa, S. S., Cameron, M. E., \& Schiffman, J. (2013, January). Current Diagnosis and Treatment of Anxiety Disorders. Retrieved October 3, 2020, from https:/www.ncbi.nlm.nih.gov/pmc/articles/PMC3628173/

Cascella, M., Rajnik, M., Cuomo, A., Dulebohn, S.C., Di Napoli, R. (2020, August 10). Features, Evaluation, and Treatment of Coronavirus (COVID-19). Retrieved September 20, 2020, from https://www.ncbi.nlm.nih.gov/books/NBK554776/

Chaudhary, R. (2017). Diathesis Stress. Encyclopedia of Animal Cognition and Behavior, 1-5.doi:10.1007/978-3-319-47829-6_53-1

Cocker, F., \& Joss, N. (2016, June 22). Compassion Fatigue among Healthcare, Emergency and Community Service Workers: A Systematic Review. Retrieved October 11, 2020, from https://www.mdpi.com/1660-4601/13/6/618

Colodro-Conde, L., Couvy-Duchesne, B., Zhu, G. et al. A direct test of the diathesis-stress model for depression. Mol Psychiatry 23, 1590-1596 (2018). https://doi.org/10.1038/mp.2017.130

Dobson, K., Szeto, A., Knaak, S., Krupa, T., Kirsh, B., Luong, D., . . . Pietrus, M. (2018, October). Mental health initiatives in the workplace: Models, methods and results from the Mental Health Commission of Canada. Retrieved October 11, 2020, from https://www.ncbi.nlm.nih.gov/pmc/articles/PMC6127746/ doi: 10.1002/wps.20574

Galbraith, N., Boyda, D., McFeeters, D., \& Hassan, T. (2020, April 28). The mental health of doctors during the COVID-19 pandemic: BJPsych Bulletin. Retrieved October 11, 2020, from https://www.cambridge.org/core/journals/bjpsych-bulletin/article/mentalhealth-of-doctors-during-the-covid19-pandemic/3259D0FF579B301246410C8627E447FD

Győrffy, Z., Dweik, D. \& Girasek, E. Workload, mental health and burnout indicators among female physicians. Hum Resour Health 14, 12 (2016). https://doi.org/10.1186/s12960-016-0108-9

Hassanzadeh, A., Heidari, Z., Feizi, A., Keshteli, A. H., Roohafza, H., Afshar, H., \& Adibi, P. (2017). Association of Stressful Life Events with Psychological Problems: A Large-Scale Community-Based Study Using Grouped Outcomes Latent Factor Regression with Latent Predictors. Computational and Mathematical Methods in Medicine,2017, 1-12. doi:10.1155/2017/3457103

Koinis, A., Giannou, V., Drantaki, V., Angelaina, S., Stratou, E., \& Saridi, M. (2015). The Impact of Healthcare Workers Job Environment on Their Mental-emotional Health. Coping Strategies: The Case of a Local General Hospital. Health psychology research, 3(1), 1984. https://doi.org/10.4081/hpr.2015.1984 
Kristman, V., Lowey, J., Fraser, L., Armstrong, S., \& Sawula, S. (2019, May 24). A multi-faceted community intervention is associated with knowledge and standards of workplace mental health: The Superior Mental Wellness @ Work study. Retrieved October 11, 2020, from https://www.ncbi.nlm.nih.gov/pmc/articles/PMC6534893/ doi: 10.1186/s12889-019-6976-X

Kumar S. (2016). Burnout and Doctors: Prevalence, Prevention and Intervention. Healthcare (Basel, Switzerland), $4(3)$, 37. https://doi.org/10.3390/healthcare4030037

Labrague, Leodoro J., and Janet De los Santos. "Fear of COVID-19, psychological distress, work satisfaction and turnover intention among front line nurses." (2020).

Lohmann, J., John, D. \& Dzay, A. (2019). Prevalence and factors associated with poor mental health among healthcare professionals in low- and lower-middle-income countries: a systematic review protocol. Syst Rev 8, 294. https://doi.org/10.1186/s13643-019-1201-7.

Lui, J., Andres, E. B., \& Johnston, J. M. (2018). Presenteeism exposures and outcomes amongst hospital doctors and nurses: a systematic review. BMC health services research, 18(1), 985. https://doi.org/10.1186/s12913-018-3789-z

Manderscheid, R. W., Ryff, C. D., Freeman, E. J., McKnight-Eily, L. R., Dhingra, S., \& Strine, T. W. (2009, December 15). Evolving Definitions of Mental Illness and Wellness. Retrieved October 3, 2020, from https://www.ncbi.nlm.nih.gov/pmc/articles/PMC2811514/

Memish, K., Martin, A., Bartlett, L., Dawkins, S., \& Sanderson, K. (2017, March 25). Workplace mental health: An international review of guidelines. Retrieved October 11, 2020, from https:/www.sciencedirect.com/science/article/abs/pii/S0091743517301159 https://doi.org/10.1016/j.ypmed.2017.03.017

Mental Health Foundation. (n.d.). Retrieved October 3, 2020, from https://www.mentalhealth.org.uk/a-to$\mathrm{z} / \mathrm{s} / \mathrm{stress} \#: \sim:$ text=Stress $\% 20$ can $\% 20$ be $\% 20$ defined $\% 20$ as ,of $\% 20$ pressures $\% 20$ that $\% 20$ are $\% 20$ unmanageable.

Mental Health in the Workplace. (2019, April 10). Retrieved October 11, 2020, from https://www.cdc.gov/workplacehealthpromotion/tools-resources/workplace-health/mental-health/index.html doi: 10.1097/JOM.0000000000001271

Morganstein, J. C., Fullerton, C. S., Ursano, R. J., Donato, D., \& Holloway, H. C. (2017). Pandemics: Health care emergencies. Textbook of Disaster Psychiatry. 2nd ed. Cambridge Univ Pr, 270-283.

Naushad, V. A., Bierens, J. J., Nishan, K. P., Firjeeth, C. P., Mohammad, O. H., Maliyakkal, A. M., . . Schreiber, M. D. (2019, October 18). A Systematic Review of the Impact of Disaster on the Mental Health of Medical Responders. National Library of Medicine, 632-643. doi:10.1017/S1049023X19004874.

Patel, K., Nadel, J., West, M. (2014). Redesigning the Care Team: The Critical Role of Frontline Workers and Models for Success. Retrieved September 20,2020, from https://www.brookings.edu/wp-content/uploads/2016/06/FINAL-Hitachi-Toolkit-32014-1 .pdf

Pappa, S., Ntella, V., Giannakas, T., Giannakoulis, V. G., Papoutsi , E., \& Katsaounou, P. (2020, August). Prevalence of Depression, Anxiety, and Insomnia Among Healthcare Workers During the COVID-19 Pandemic: A Systematic Review and Meta-analysis. Brain, Behavior, and Immunity, 88, 901-907. doi:https://doi.org/10.1016/j.bbi.2020.05.026

Paykel, E. S. (2008, September). Basic Concepts of Depression. Dialogues in Clinical Neuroscience, 279-289. Retrieved October 3, 2020, from https://www.ncbi.nlm.nih.gov/pmc/articles/PMC3181879/

Pfeefferbaum, B., North, C.S. (2020, August 06). Mental Health and the Covid-19 Pandemic. The New England Journal Of Medicine. doi: 10.1056/NEJMp2008017.

Rajkumar, R. P. (2020, August). COVID-19 and Mental Health: A Review of the Existing Literature. Asian Journal of Psychiatry. doi:https://doi.org/10.1016/j.ajp.2020.102066

Sachiko, K. (2016). Workers' Mental Health, Long Work Hours, and Workplace Management: Evidence from workers' longitudinal data in Japan. Retrieved 2020, from https://www.rieti.go.jp/jp/publications/dp/16e017.pdf

Salari, N., Hosseinian-Far, A., Jalali, R. et al. Prevalence of stress, anxiety, depression among the general population during the COVID19 pandemic: a systematic review and meta-analysis. Global Health 16, 57 (2020). https://doi.org/10.1186/s12992-020-00589-w

Sasaki, N., Kuroda, R., Tsuno, K., \& Kawakami, N. (2020, January). Workplace responses to COVID-19 associated with mental health and work performance of employees in Japan. Retrieved October 11, 2020, from https://www.ncbi.nlm.nih.gov/pmc/articles/PMC7289653/ doi: 10.1002/1348-9585.12134

Schneiderman, N., Ironson, G., \& Siegel, S. D. (2008, October 16). Stress and Health: Psychological, Behavioral, and Biological Determinants. doi: 10.1146/annurev.clinpsy.1.102803.144141

Serafini, G., Parmigiani, B., Amerio, A., Aguglia, A., Sher, L., Amore, M. (2020, June 30). The Psychological Impact of COVID-19 on the Mental Health in the General Population. An International Journal of Medicine, 113(8), 531-537. https://doi.org/10.1093/qjmed/hcaa201.

Serrano-Ripoll, M. J., Meneses-Echavez, J. F., Ricci-Cabello, I., Fraile-Navarro, D., Fiol-deRoque, M. A., Pastor-Moreno, G., Castro, A., Ruiz-Pérez, I., Zamanillo Campos, R., \& Gonçalves-Bradley, D. C. (2020). Impact of viral epidemic outbreaks on mental health of healthcare workers: a rapid systematic review and meta-analysis. Journal of affective disorders, 277, 347-357. Advance online publication. https://doi.org/10.1016/j.jad.2020.08.034

Simpson J, Weiner E, editors. Oxford English dictionary. Cary, NC: Oxford University Press; 1989

Singhal, T. (2020, March 13). A Review of Coronavirus Disease-2019 (COVID-19). Retrieved September 20, 2020, from https://www.ncbi.nlm.nih.gov/pmc/articles/PMC7090728/

Spoorthy, M. S., Pratapa, S. K., \& Mahani, S. (2020, April 22). Mental Health Problems Faced by Healthcare Workers Due to the COVID-19 Pandemic - A Review. Elsevier Public Health Emergency Collection. doi:doi: 10.1016/j.ajp.2020.102119 
Tee, M. L., Tee, C. A., Anlacan, J. P., Aligam, K. J., Reyes, P. C., Kuruchittham, V., \& Ho, R. C. (2020). Psychological Impact of COVID-19 Pandemic in the Philippines. Journal of Affective Disorders, 277, 379-391. doi:https://doi.org/10.1016/j.jad.2020.08.043

Thibaut, F. (2017, June). Anxiety Disorders: A Review of Current Literature. Dialogues in Clinical Neuroscience, 87-88. Retrieved October 3, 2020, from https://www.ncbi.nlm.nih.gov/pmc/articles/PMC5573565/

Tomer, A., Kane, J.W. (2020, June 10). To Protect Frontline Workers During and After COVID-19, We Must Define Who They Are. Retrieved September 20, 2020, from https://www.brookings.edu/research/to-protect-frontline-workers-during-and-after-covid-19we-must-define-who-they-are/

Torales, J., O’Higgins, M., Castaldelli-Maia, J. M., \& Ventriglio, A. (2020). The outbreak of COVID-19 coronavirus and its impact on global mental health. International Journal of Social Psychiatry, 66(4), 317-320. https://doi.org/10.1177/0020764020915212

Vigo, D., Patten, S., Pajer, K., Krausz, M., Taylor, S., Rush, B., Ravioli, G., Saxena, S., Thornicroft, G., \& Yatham, L. N. (2020). Mental Health of Communities During the COVID-19 Pandemic. The Canadian Journal of Psychiatry. doi:https://doi.org/10.1177/0706743720926676

Walcott, D. \& Schamroth, J. (2020). Here's Why Developing Countries Should Embrace Value-Based Healthcare After The Coronavirus Pandemic. Retrieved September 01, 2020, from https://www.forbes.com/sites/davidwalcott/2020/07/22/heres-why-developingcountries-should-embrace-value-based-healthcare-after-the-coronavirus-pandemic/

World Health Organization. (2020). Coronavirus disease (COVID-19) in the Philippines. Retrieved September 01, 2020, from https://www.who.int/philippines/emergencies/covid-19-in-the-philippines

World Health Organization. (n.d.). Health. Retrieved September 20, 2020, from https://www.who.int/about/who-we-are/constitution

World Health Organization (2018). Mental Health: Strengthening Our Response. Retrieved from https://www.who.int/news-room/factsheets/detail/mental- health-strengthening-our-response

World Health Organization. (2020). Philippines: WHO Coronavirus Disease (COVID-19) Dashboard. Retrieved September 01, 2020, from https://covid19.who.int/region/wpro/country/ph

World Health Organization. (2012, May 11). WHO I WHO urges more investments, services for mental health. https://www.who.int/mental_health/who_urges_investment/en/\#:\%7E:text=WHO\%2FP.,to\%20her\%20or\%20his\% 